\title{
PENINGKATAN PENGENDALIAN KUALITAS MELALUI METODE LEAN SIX SIGMA
}

\author{
Purnawan Adi Wicaksono*), Diana Puspita Sari, Naniek Utami Handayani, Heru \\ Prastawa, Anugra Dewa Ramadhan
}

\author{
Departemen Teknik Industri, Fakultas Teknik, Universitas Diponegoro \\ Jl. Prof. H. Soedarto, SH., Tembalang, Semarang
}

(Received: August 28, 2017/ Accepted: September 22, 2017)

\begin{abstract}
Abstrak
PT. Coca-Cola Amatil Indonesia (PT. CCAI) merupakan perusahaan yang bergerak di bidang minuman ringan dalam kemasan. Perusahaan ini menjadi pusat produksi produk Coca-Cola regional Jawa Tengah. Berbagai macam produk seperti Coca-Cola, Fanta, Sprite, Minute Maid dan Frestea diproduksi demi memenuhi kebutuhan pelanggan. Produk-produk tersebut tentunya tidak terlepas dari permasalahan produk cacat, dimana dalam produksinya terdapat produk yang tidak sesuai dengan standar ketetapan produk. Secara umum, produk cacat PT.CCAI dibagi menjadi tiga tipe, yakni cap, cap quality, dan underfill. Dari hasil analisis yang dilakukan, produk Coca-Cola $1000 \mathrm{ml}$ memiliki jumlah cacat yang paling besar, yakni 0,49\%. Penyebab terbesar dari terjadinya cacat produk pada produk Coca-Cola $1000 \mathrm{ml}$ adalah underfill, dimana volume dari produk yang dihasilkan tidak sesuai dengan batas minimal. Permasalahan tersebut diselesaikan menggunakan konsep Lean Six Sigma dengan menggunakan tools diagram Pareto dan diagram tulang ikan. Dari hasil analisis menggunakan tools tersebut, PT. CCAI Semarang disarankan untuk memberikan pelatihan-pelatihan mengenai manajemen waktu pada karyawankaryawannya, terutama pada karyawan-karyawan baru. Selain itu, PT. CCAI Semarang harus juga melakukan pengecekan mesin yang lebih rutin dan lebih memperhatikan lingkungan area produksi.
\end{abstract}

Kata Kunci : Lean Six Sigma, Diagram Pareto, Fishbone

\section{Pendahuluan}

PT. Coca Cola Amatil Indonesia (CCAI) Semarang merupakan perusahaan yang bergerak di bidang minuman kemasan. Perusahaan ini menjadi pusat produksi produk Coca-Cola regional Jawa Tengah. Berbagai macam produk seperti Coca-Cola, Fanta, Sprite, Minute Maid dan Frestea diproduksi demi memenuhi kebutuhan pelanggan. Di lantai produksinya, PT. CCAI memiliki 4 lintasan aktif yang dapat digunakan untuk memproduksi produk, yakni lintasan 4, 5, 6, dan 8. Setiap lintasan memiliki hasil produk yang berbeda, misal lintasan 4 digunakan untuk memproduksi minuman soda dalam kaleng, lintasan 5 minuman non-carbonated, lintasan 6 minuman soda dalam botol plastik, dan lintasan 8 minuman dalam botol kaca.

Permasalahan mendasar dalam setiap lintasan adalah adanya produk cacat dalam setiap produksi. Berdasarkan survei lapangan dan wawancara yang telah dilakukan, operator dan supervisor mengatakan bahwa keempat lintasan tersebut rata-rata memiliki tingkat cacat yang sama. Hal ini dikarenakan pihak PT.CCAI sebenarnya tidak mempunyai data mengenai lintasan mana yang memiliki rata-rata produk cacat paling banyak.

\footnotetext{
*) Penulis Korespondensi.

E-mail: nawanadi@gmail.com
}

Penelitian ini akan dilakukan pada lintasan 6. Hal ini dikarenakan pihak Coca-Cola memiliki data yang lebih lengkap mengenai produksi per bulannya di lintasan 6 dibandingkan dengan lintasan lain. Selain itu, lintasan 6 merupakan lintasan yang masih tergolong baru, dimana rata-rata mesin di lintasan ini merupakan mesin tahun 2006. Produk-produk yang dihasilkan di lintasan 6 hanya terdiri dari tiga jenis, yakni Coca-Cola, Fanta, dan Sprite. Ketiga merek tersebut diproduksi dengan masing-masing varian volume $390 \mathrm{ml}, 1000 \mathrm{ml}$, dan $1500 \mathrm{ml}$. Dari berbagai varian tersebut, Coca-Cola $1000 \mathrm{ml}$ memiliki ratarata prosentase cacat tertinggi pada tahun 2016. Prosentase tersebut bernilai 0,49 persen, dimana batas kewajaran prosentase cacat hanya sebesar 0,2 persen. Angka ini tentunya melebihi batas wajar cacat yang ditentukan.

Beberapa kerugian yang diakibatkan oleh banyaknya produk cacat diantaranya adalah berkurangnya keuntungan, bertambahnya materialmaterial yang gagal diubah menjadi produk jadi, serta menambah biaya untuk pengolahan material gagal. Tujuan dari penelitian ini adalah menganalisa jumlah produksi, jumlah cacat, proporsi cacat, penyebab cacat, serta memberikan rekomendasi pada produksi Coca-Cola $1000 \mathrm{ml}$.

Penelitian ini membahas mengenai permasalahan produk cacat yang terjadi di lintasan 6 PT. CCAI Semarang khususnya pada produk Coca-Cola 1000 
ml. Hal ini dikarenakan tingkat prosentase cacatdari produk Coca-Cola $1000 \mathrm{ml}$ memiliki angka yang melebihi prosentase cacat standar.

\section{Studi Literatur}

Kombinasi Lean dan Six Sigma semakin mendapatkan pengakuan oleh para ahli dalam menyelesaikan permasalahan identifikasi dan eliminasi defect product serta pengukuran sistem kualitas (Hu et al, 2008). Six Sigma yang dikombinasikan dengan filosofi Lean menyajikan solusi untuk menangani problem secara spesifik yang telah diidentifikasikan sebelumnya (Wheat, Mills, \& Carnell, 2003). Six Sigma memiliki lima fase yang digunakan untuk mengatasi permasalahan secara spesifik. Berikut adalah langkah-langkahnya (A Thomas et al, 2009) :

1. Define, meliputi konsumen, prioritas konsumen, permasalahan konsumen, hingga solusinya.

2. Measure, melakukan pengukuran terhadap performansi proses.

3. Analyze, menganalisis akar penyebab permasalahan.

4. Improve, melakukan pendesainan ulang terhadap proses dan melakukan uji terhadapnya.

5. Control, melakukan pengendalian terhadap pengembangan-pengembangan yang dilakukan serta menyingkirkan penghalangpenghalangnya.

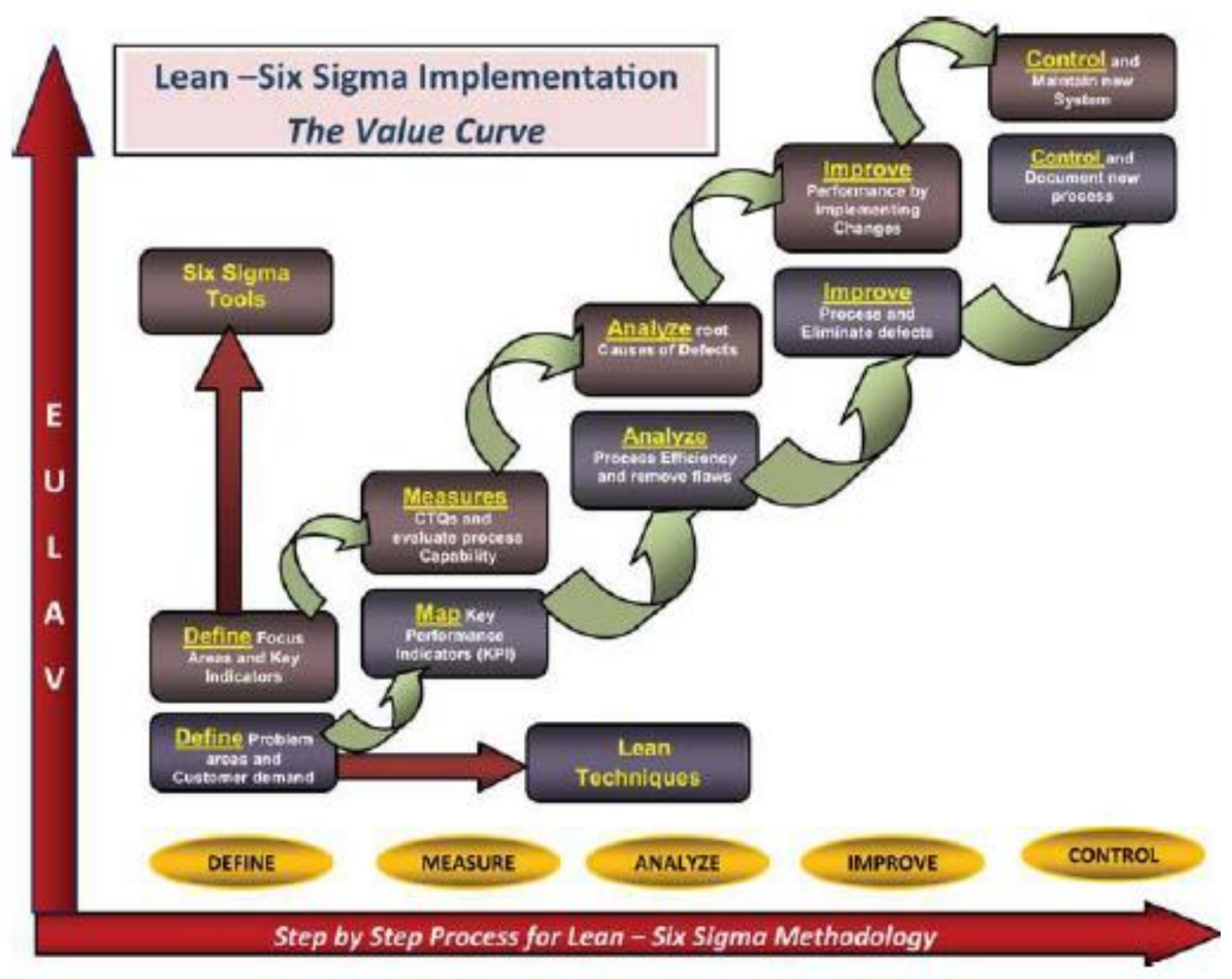

Gambar 1. Kurva Lean Six Sigma

Lean merupakan sebuah filosofi manufaktur yang berfokus pada pemberian produk berkualitas tinggi secara tepat waktu dan biaya terendah (Liker, 2004). Lean didefinisikan sebagai alat untuk menghilangkan waste secara sistematis yang dilaksanakan oleh seluruh anggota organisasi (Worley \& Doolen, 2006). Filosofi lean bergantung pada pendekatan lima fase, diantaranya (A Thomas et al, 2009):

1. Identifikasi nilai

2. Ukur value stream
3. Melakukan penarikan terhadap permintaan konsumen

4. Membuat aliran

5. Mencapai kesempurnaan

Lean manufacturing membutuhkan tidak hanya pemahaman teknis secara menyeluruh dari sistem manufaktur, tetapi juga membutuhkan pemahaman mengenai hubungan yang ada antara manufaktur dan area-area lain dalam perusahaan seperti manajemen rantai pasok, permintaan dan persepsi konsumen, distribusi dan logistik (Womack \& Jones, 1994). 
Contoh penggunaan dari kombinasi antara Lean dan Six Sigma terjadi pada kasus perusahaan manufaktur ban di India. Pada kasus tersebut, Lean Six Sigma digunakan untuk mengatasi permasalahan defect tyre seperti adanya lubang, sobekan, serta gelembung dalam ban (Gupta et al, 2012).

\section{Metodologi}

Penelitian ini dimulai dengan mempelajari aktivitas-aktivitas produksi yang ada di PT. CCAI. Setelah semua aktivitas produksi teridentifikasi, peneliti mengidentifikasi masalah-masalah pada proses produksi dan peyebab-penyebabnya.
Kemudian, apabila sudah dilakukan identifikasi masalah, maka penelitian dilanjutkan dengan melakukan observasi lapangan dan studi pustaka untuk mendapatkan data-data yang relevan. Setelah data-data yang relevan didapatkan, maka data-data tersebut diolah kemudian dilanjutkan dengan menganalisisnya. Setelah itu, penelitian memasuki tahap terakhir, yakni pemberian kesimpulan dan saran.

\section{Hasil dan Pembahasan}

Berikut ini perbandingan rata-rata cacat produk yang dihasilkan lintasan 6 dalam setahun :

Tabel 1. Perbandingan Rata-Rata Cacat Produk Lintasan 6

\begin{tabular}{clll}
\hline Volume (ml) & \multicolumn{1}{c}{ Produk } & Rata-rata Prosentase Cacat Setahun (\%) \\
\hline \multirow{3}{*}{390} & Fanta stb & 0,09 \\
\cline { 2 - 3 } & Sprite & 0,19 \\
\cline { 2 - 3 } & Coke & 0,24 \\
\hline \multirow{3}{*}{1000} & Fanta stb & 0,34 \\
\cline { 2 - 3 } & Sprite & 0,06 \\
\cline { 2 - 3 } & Coke & 0,49 \\
\hline \multirow{3}{*}{1500} & Fanta stb & 0,18 \\
\cline { 2 - 3 } & Sprite & 0,13 \\
\cline { 2 - 3 } & Coke & 0,28 \\
\hline
\end{tabular}

Tabel 2. Produksi Coca-Cola $1000 \mathrm{ml}$

\begin{tabular}{|c|c|c|c|c|c|c|c|c|c|c|c|c|}
\hline \multirow{3}{*}{$\begin{array}{l}\text { Tanggal } \\
\text { Produksi }\end{array}$} & \multicolumn{2}{|c|}{ Jumlah Diproduksi } & \multicolumn{6}{|c|}{ Cacat } & \multicolumn{2}{|c|}{ Total Cacat } & \multicolumn{2}{|c|}{$\begin{array}{l}\text { Prosentase } \\
\text { Cacat }(\%)\end{array}$} \\
\hline & \multirow{2}{*}{ Box } & \multirow{2}{*}{ Pes } & \multicolumn{2}{|c|}{ C } & \multicolumn{2}{|c|}{ cQ } & \multicolumn{2}{|c|}{ Uf } & \multirow{2}{*}{ Box } & \multirow{2}{*}{ Pcs } & \multirow{2}{*}{ Box } & \multirow{2}{*}{ Pes } \\
\hline & & & Box & Pes & Box & Pes & Box & Pes & & & & \\
\hline 29-Des-16 & 2837 & 34040 & 1,67 & 20 & 0,08 & 1 & 41,58 & 499 & 43,33 & 520 & 1,53 & 1,53 \\
\hline 22-Des-16 & 3513 & 42156 & 5,33 & 64 & 1,5 & 18 & 6,17 & 74 & 13 & 156 & 0,37 & 0,37 \\
\hline 11-Okt-16 & 5500 & 66000 & 16,67 & 200 & 15,67 & 188 & 13,75 & 165 & 46,09 & 553 & 0,84 & 0,84 \\
\hline $10-$ Okt-16 & 5134 & 61608 & 10,08 & 121 & 5,58 & 67 & 38,17 & 458 & 53,83 & 646 & 1,05 & 1,05 \\
\hline 18-Sep-16 & 5122 & 61464 & 4 & 48 & 2,5 & 30 & 17,58 & 211 & 24,08 & 289 & 0,47 & 0,47 \\
\hline 02-Sep-16 & 4272 & 51554 & 0,08 & 1 & 0,25 & 3 & 4,33 & 52 & 4,67 & 56 & 0,11 & 0,11 \\
\hline 23-Jun-16 & 15288 & 183456 & 14,4 & 168 & 1,5 & 18 & 35,25 & 423 & 51,15 & 609 & 0,33 & 0,33 \\
\hline 18-Jun-16 & 13195 & 158329 & 15,58 & 187 & 6,17 & 74 & 30,17 & 362 & 51,92 & 623 & 0,39 & 0,39 \\
\hline 09-Jun-16 & 20689 & 248268 & 2,33 & 28 & 1,42 & 17 & 14,58 & 175 & 18,33 & 220 & 0,09 & 0,09 \\
\hline 07-Mei-16 & 32592 & 393952 & 31,50 & 378 & 37,58 & 451 & 69,50 & 834 & 138,58 & 1663 & 0,43 & 0,42 \\
\hline 29-Apr-16 & 10240 & 122880 & 5,33 & 64 & 1,25 & 15 & 12,75 & 153 & 19,33 & 232 & 0,19 & 0,19 \\
\hline 19-Apr-16 & 12509 & 150102 & 0,83 & 10 & 7,08 & 85 & 22,33 & 268 & 30,25 & 363 & 0,24 & 0,24 \\
\hline 12-Apr-16 & 3906 & 46872 & 2,92 & 35 & 2,33 & 28 & 15,25 & 183 & 20,5 & 246 & 0,52 & 0,52 \\
\hline 28-Mar-16 & 3893 & 46711 & 6,75 & 81 & 3,42 & 41 & 4,50 & 54 & 14,67 & 176 & 0,38 & 0,38 \\
\hline 10-Feb-16 & 6428 & 77135 & 10,42 & 125 & 1,50 & 18 & 13,83 & 166,00 & 25,75 & 309 & 0,40 & 0,40 \\
\hline Jumlah & 145118 & 1744527 & 128 & 1530 & 88 & 1054 & 340 & 4077 & 555 & 6661 & & \\
\hline \multicolumn{9}{|c|}{ Rata-Rata } & & & 0,49 & 0,49 \\
\hline \multicolumn{11}{|c|}{ Standar Deviasi } & 0,38 & 0,38 \\
\hline
\end{tabular}


Dari Tabel 1 tersebut, diketahui bahwa Coca-Cola $1000 \mathrm{ml}$ menghasilkan produk cacat paling banyak, yakni dengan prosentase sebesar 0,49 persen setahun. Tabel 2 disajikan produksi Coca-Cola $1000 \mathrm{ml}$ tahun 2016.

Dari data Tabel 2 tersebut diketahui bahwa ratarata prosentase produk cacat adalah 0,49 dengan standar deviasi sebesar 0,38. Sebelum dilakukan penghitungan kapabilitas proses, maka perlu dilakukan pengecekan apakah data berdistribusi normal dan terkontrol secara statistik. Peta kendali yang digunakan dalam kasus ini adalah peta kendali P. Gambar 2 disajikan Peta P Coca-Cola $1000 \mathrm{ml}$.

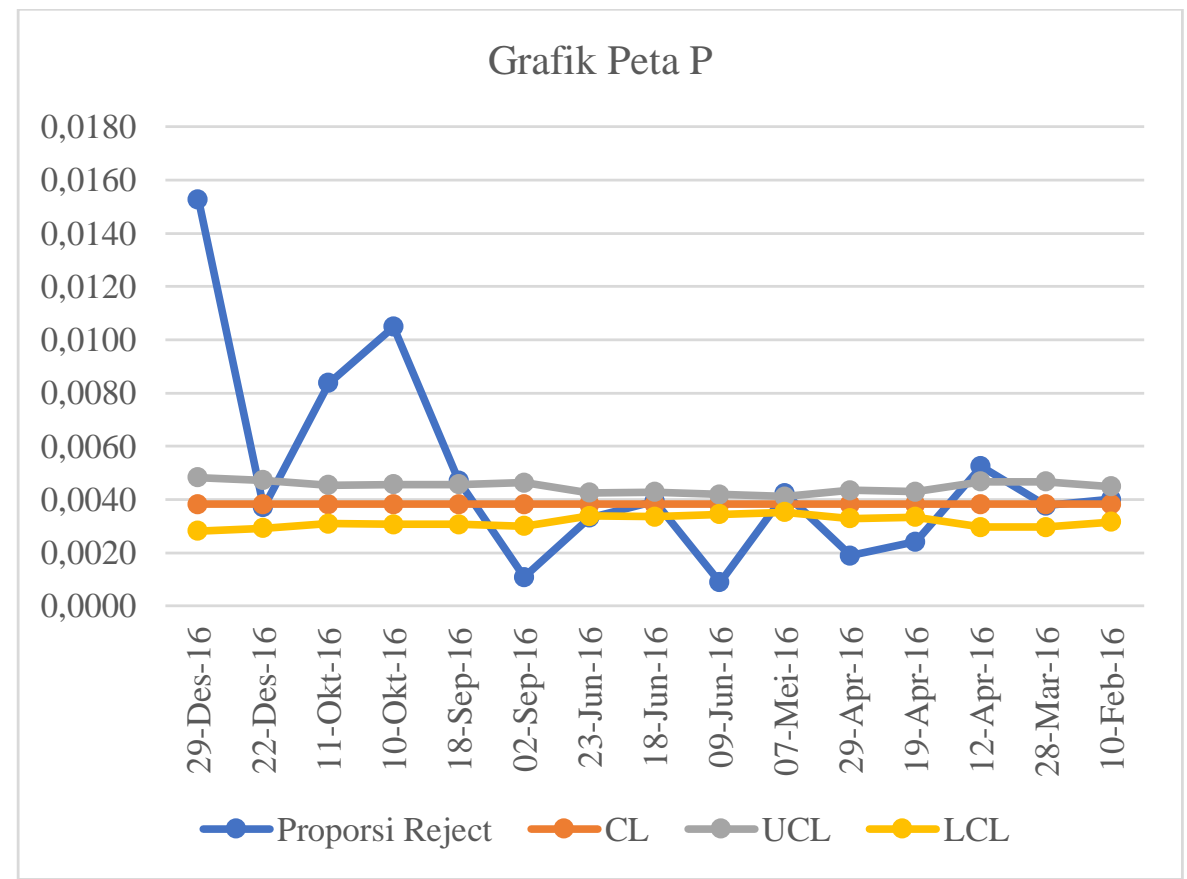

Gambar 2. Grafik Peta P

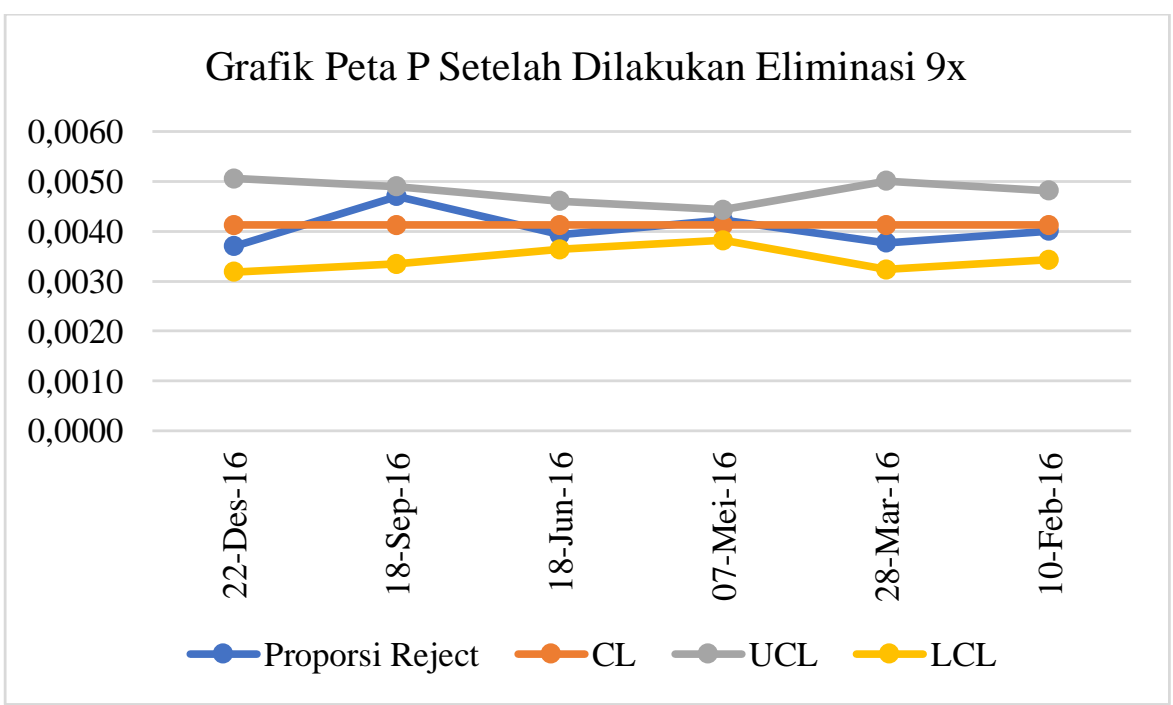

Gambar 3. Grafik Peta P Setelah Eliminasi

Dikarenakan dalam Peta P tersebut masih terdapat data yang berada di luar batas kendali, maka data terekstrim perlu dieliminasi. Data paling ekstrim dari grafik tersebut ditunjukkan pada produksi pertama, yakni pada tanggal 29 Desember 2016. Data akan dilakukan eliminasi secara terus-menerus hingga tidak ada data yang berada di luar batas kendali. Pada penelitian ini, data dieliminasi sebanyak 9 kali sehingga hanya menyisakan 6 data. Gambar 3 adalah hasil dari Peta $\mathrm{P}$ setelah data ekstrim tersebut dieliminasi.

Setelah semua data berada di batas kendali, dilakukan pengecekan distribusi normal terhadap data yang telah dieliminasi tersebut. Gambar 4 adalah 
hasil pengecekan distribusi normal menggunakan software Minitab. Dari grafik tersebut diketahui bahwa nilai $\mathrm{P}$ adalah 0,377 sehingga data telah terdistribusi normal dikarenakan nilai $\mathrm{P}$ melebihi nilai alfa (0,005). Selanjutnya dilakukan penghitungan $C_{p}$ dan $\mathrm{C}_{\mathrm{pk}}$ menggunakan software Minitab. Gambar 5 adalah hasil dari penghitungan $C_{p}$ dan $C_{p k}$.

Gambar 5 tersebut menunjukkan bahwa nilai $C_{p}$ sebesar 0,68 dan nilai $C_{p k}$ sebesar $-1,41$. Nilai $C_{p k}$ yang kurang dari 1 menandakan bahwa proses tersebut tidak kapabel, sedangkan nilai $\mathrm{C}_{\mathrm{p}}$ dan $\mathrm{C}_{\mathrm{pk}}$ yang memiliki rentang jauh mengindikasikan bahwa proses tidak berkumpul di tengah, namun berada di luar batas spesifikasi. Hasil penghitungan $\mathrm{C}_{\mathrm{p}}$ dan $\mathrm{C}_{\mathrm{pk}}$ ini menunjukkan bahwa dalam produksi Coca-Cola $1000 \mathrm{ml}$ masih perlu dilakukan tindakan perbaikan.

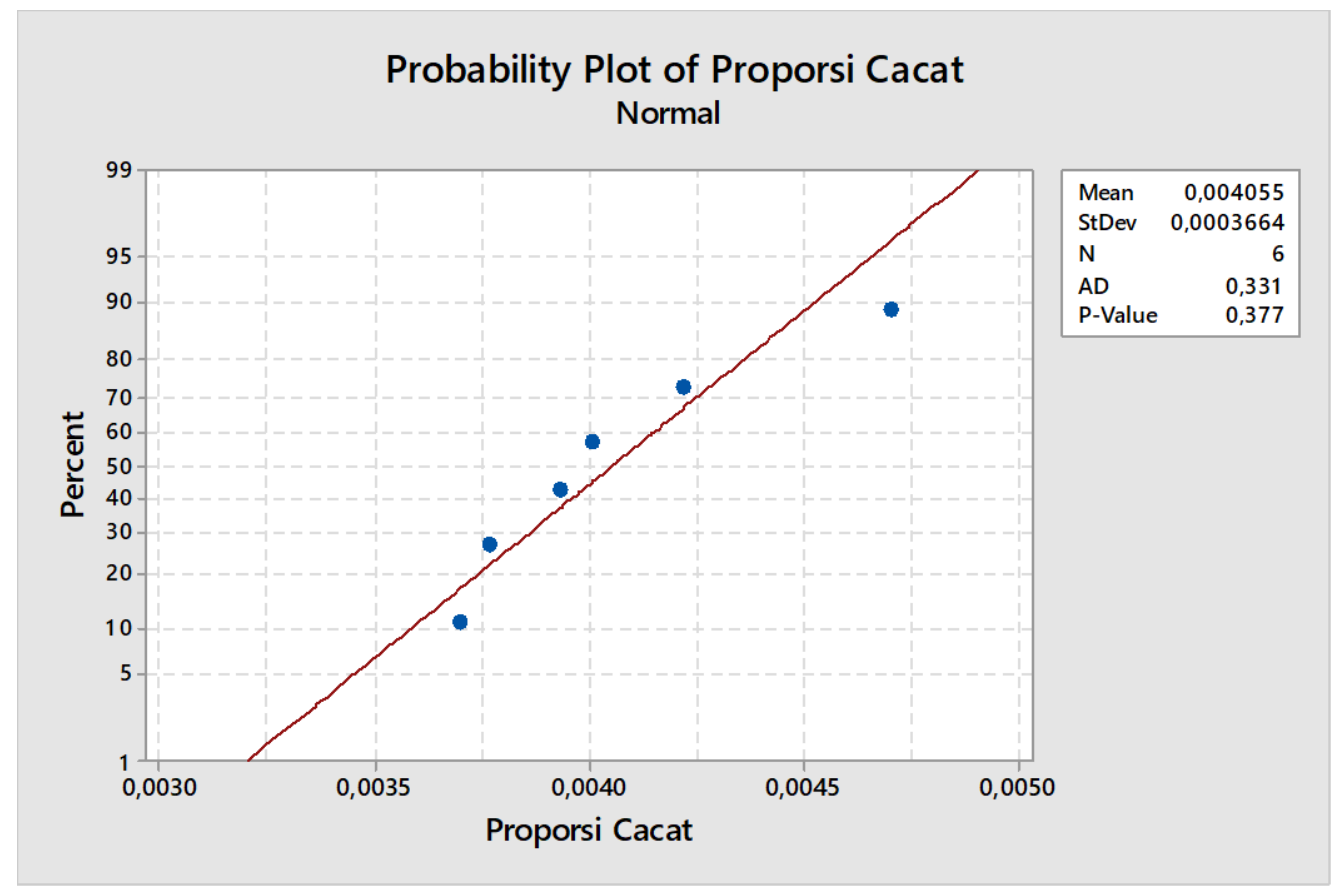

Gambar 4. Distribusi Normal Minitab

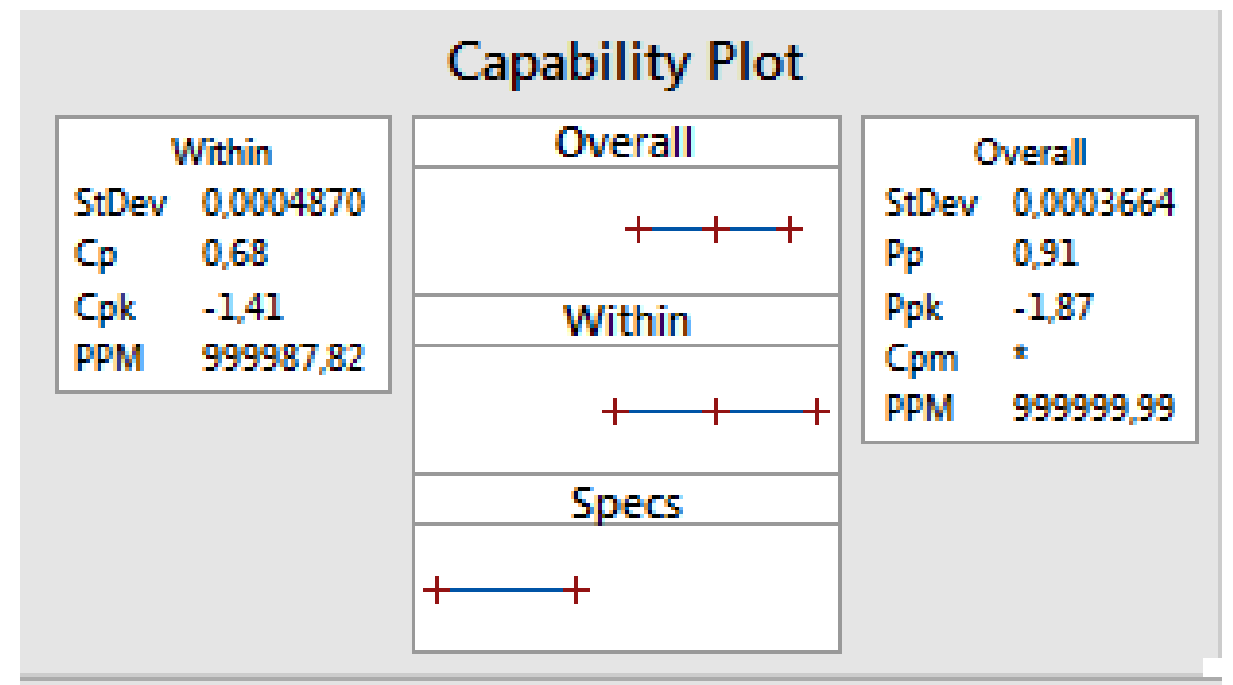

Gambar 5. Hasil $\mathrm{C}_{\mathrm{p}}$ dan $\mathrm{C}_{\mathrm{pk}}$ Minitab

Tabel 3. Rekapitulasi Jumlah Cacat Coca-Cola 1000 ml Tahun 2016

\begin{tabular}{lcc}
\hline Jenis Cacat & Jumlah (pcs) & Prosentase (\%) \\
\hline Cap & 1530 & 22,97 \\
\hline Cap Quality & 1054 & 15,82 \\
\hline Underfill & 4077 & 61,21 \\
\hline Total & 6661 & 100 \\
\hline
\end{tabular}




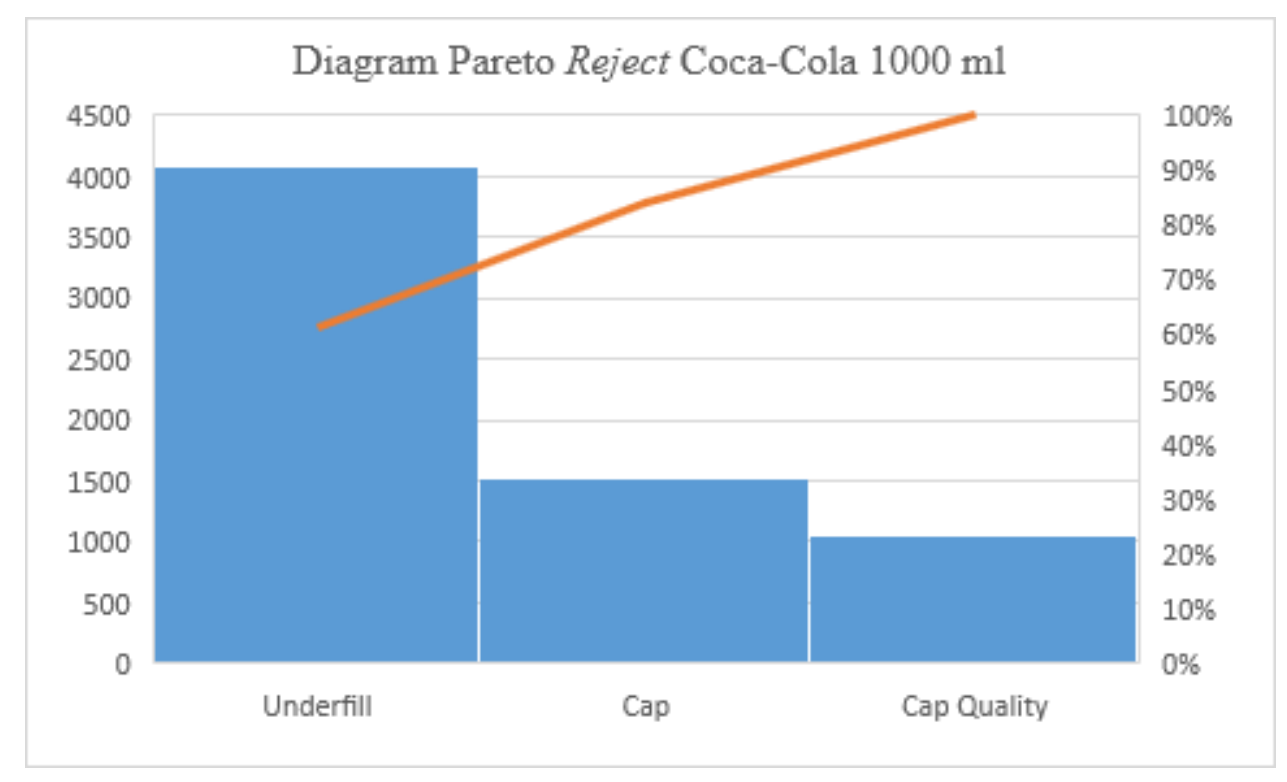

Gambar 6. Diagram Pareto

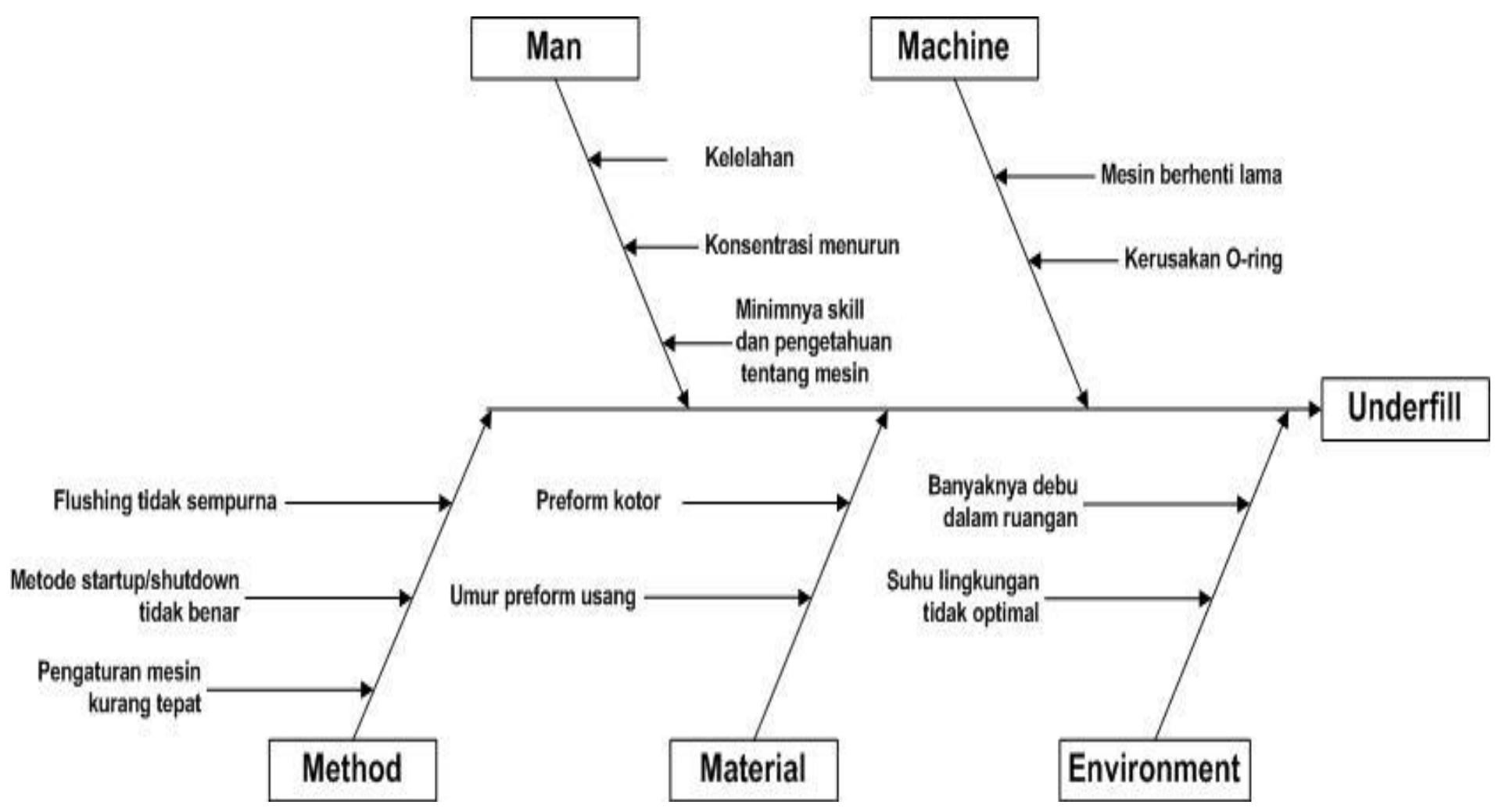

Gambar 7. Diagram Tulang Ikan 


\section{Pembuatan Diagram Pareto}

Pembuatan Diagram Pareto diawali dengan mengetahui penyebab cacat terbanyak. Tabel 3 menyajikan rekapitulasi jumlah cacat selama 2016. Gambar 6 merupakan Diagram Pareto yang disusun berdasarkan Tabel 3.

\section{Pembuatan Diagram Tulang Ikan}

Pembuatan Diagram Tulang Ikan akan dilakukan pada permasalahan terbesar pada Diagram Pareto. Berdasarkan Pareto pada penelitian ini, penyebab terbesar dari produk cacat adalah underfill. Diagram Tulang Ikan dari permasalahan underfill dapat dilihat pada Gambar 7.

Gambar 7 menjelaskan bahwa ada lima aspek yang perlu diperbaiki demi mengurangi underfill, yakni aspek manusia (man), mesin (machine), metode (method), material, serta lingkungan (environment). Masing-masing dari aspek tersebut memiliki sub aspek yang perlu diperbaiki untuk meningkatkan kapabilitas produksi Coca-Cola $1000 \mathrm{ml}$.

\section{Implementasi Jidoka}

Jidoka merupakan konsep dimana mesin dan manusia bekerja bersama untuk menyelesaikan permasalahan. Mesin akan bekerja secara otomatis untuk mengendalikan kualitas produk, sedangkan manusia akan mengerjakan aktivitas yang lebih tinggi nilainya. Secara teknis, jidoka dapat diimplementasikan salah satunya dengan menggunakan Diagram Tulang Ikan sebagai acuan penyelesaian masalah.

Berdasarkan Diagram Tulang Ikan yang telah dibuat, ada beberapa permasalahan dari aspek manusia yang perlu diperhatikan agar dapat mengurangi tingkat underfill Coca-Cola $1000 \mathrm{ml}$, diantaranya adalah kelelahan, konsentrasi menurun, serta minimnya skill dan pengetahuan operator tentang mesin yang bersangkutan. Permasalahanpermasalahan tersebut dapat dicegah dengan cara melatih karyawan agar memiliki manajemen waktu yang baik serta memberikan pelatihan-pelatihan kepada karyawan baru mengenai mesin-mesin produksi. Selain itu, untuk meminimalisir kesalahan akibat minimnya pengetahuan dan skill tentang mesin dapat pula diatasi dengan memberikan seorang partner karyawan lama kepada karyawan baru.

Sedangkan dari aspek mesin, penyebab terjadinya underfill adalah akibat mesin yang berhenti lama atau kerusakan pada $O$-ring. $O$-ring merupakan suatu part dalam mesin pengisi yang berfungsi untuk mengatur volume pengisian. Mesin yang berhenti lama dapat dicegah dengan melakukan penggunaan mesin yang sesuai dengan Standard Operation Procedure (SOP).
Sedangkan apabila terjadi permasalahan terhadap $O$-ring, penanganan dapat dilakukan dengan cara mengganti $O$-ring mesin. Melakukan penggantian $O$ ring secara rutin juga merupakan langkah yang baik untuk mencegah terjadinya kerusakan $O$-ring .

\section{Kesimpulan dan Saran}

Coca-Cola $1000 \mathrm{ml}$ diproduksi sebanyak 15 kali pada tahun 2016 dengan jumlah produksi box sebanyak 145.118 atau setara dengan 1.744 .527 pcs. Dari 1.744.527 pcs Coca-Cola $1000 \mathrm{ml}$ yang diproduksi, 6.661 pcs adalah produk cacat. Proporsi cacat yang terjadi pada produksi Coca-Cola $1000 \mathrm{ml}$ pada tahun 2016 adalah sebesar 0,49 persen. Penyebab cacat dari Coca-Cola $1000 \mathrm{ml}$ terdiri atas cap cacat, cap quality cacat, serta underfill cacat dengan proporsi terbesar terjadi pada keadaan underfill dengan prosentase $61,21 \%$, diikuti dengan cap cacat $22,97 \%$, dan cap quality cacat $15,82 \%$. Terdapat beberapa aspek yang perlu diperbaiki dalam produksi Coca-Cola $1000 \mathrm{ml}$, diantaranya aspek manusia, mesin, metode, material, serta aspek lingkungan.

Setelah dilakukan penelitian ini, ada beberapa tindakan yang dapat dilakukan oleh PT.CCAI untuk mengurangi cacat pada Coca-Cola 1000ml. PT. CCAI Semarang harus memberikan pelatihan-pelatihan mengenai manajemen waktu pada karyawankaryawannya, terutama pada karyawan-karyawan baru serta memberikan seorang partner karyawan lama kepada karyawan baru. Hal ini dilakukan agar karyawan-karyawan baru PT. CCAI Semarang dapat melakukan adaptasi terhadap pembagian shift yang ada di PT. CCAI lebih cepat.

Selain itu, PT. CCAI Semarang harus melakukan pengecekan mesin lebih rutin dan lebih teliti agar mampu meninimalisir kerusakan yang terjadi. PT. CCAI Semarang disarankan untuk lebih memperhatikan lingkungan area produksi. Hal ini dilakukan agar kegiatan produksi dalam PT. CCAI lebih resik.

Kekurangan dari penelitian ini adalah data yang didapatkan terlalu sedikit, yakni hanya 15 data dalam satu tahun. Dalam penelitian selanjutnya diharapkan dapat menggunakan data yang lebih banyak sehingga penelitian lebih terpercaya. Selain itu, diharapkan pula dalam penelitian selanjutnya untuk mengidentifikasi penyebab cacat selain underfill.

\section{Refrensi}

A Thomas et al. (2009). Applying Lean Six Sigma in a Small Engineering Company - a model for change. Journal of Manufaturing Technology Management, 113-29. 
Gupta, V., Acharya, P., \& Patwardhan, M. (2012). Monitoring Quality Goals through Lean SixSigma Insures Competitiveness. International Journal of Productivity and Performance Management, 194-203.

Hu et al. (2008). A Multi-Objective Model for Project Portfolio Selection to Implement Lean and Six Sigma Concepts. International Journal of Production Research, 6611-25.

Liker, J. (2004). The Toyota Way : 14 Management Principles form the World's Greatest Manufaturer. New York: McGraw-Hill.
Wheat, B. (2003). Leaning into Six Sigma : A Parable of the Journey to Six Sigma and a Lean Enterprise. New York: McGraw-Hill.

Womack, J. P., \& Jones, D. T. (1994). From Lean Production to the Lean Enterprise. Harvard Business Review, 93-103.

Worley, J. M., \& Doolen, T. L. (2006). The Role of Communication and Management Support in a Lean Manufacturing Implementation . Management Decision, 228-45. 